\title{
Does the Stress of Exams Period Influence Medical Student’ s Blood Pressure? A Longitudinal Study
}

Thauler Alves De Oliveira ${ }^{1 *}$, Kenia Ferreira Rosa ${ }^{1}$, Otávio Antoniel Vilela Nunes ${ }^{1}$, Guilherme Augusto Alves de Oliveira $^{2}$ and Flávio Ricardo Manzi $^{3}$

${ }^{1}$ School of Medicine, University of Itaúna, Itaúna, MG, Brazil

${ }^{2}$ Department of Clinical Dentistry and Periodontics, "Pontíficia Universidade Católica de Minas Gerais", Belo Horizonte, Brazil

${ }^{3}$ Department of Dental Radiology, "Pontíficia Universidade Católica de Minas Gerais”, Belo Horizonte, Brazil

"Corresponding author: Thauler Alves De Oliveira, School of Medicine, University of Itaúna, 47 João Dornas, Centro, Itaúna, Minas Gerais, Brazil, Tel: +5537998643311; E-mail: guilherme_augusto.o@hotmail.com

Rec date: December 11, 2017; Acc date: January 18, 2018; Pub date: January 22, 2018

Copyright: (c) 2018 Alves De Oliveira T, et al. This is an open-access article distributed under the terms of the Creative Commons Attribution License, which permits unrestricted use, distribution, and reproduction in any medium, provided the original author and source are credited.

\begin{abstract}
Background: Based on relation of pathological effects of stress on the body and its reflex on blood pressure, the high level of stress undergone by medical students becomes a concern about quality of medical training and its health. The aim is to verify the possible influence of stress during exam periods on the blood pressure of medical students.
\end{abstract}

Method: The systemic arterial pressure (SAP) of 109 medical students of an institution was measured and analyzed in the period from March to September 2016, using the standardization recommended by the American Heart Association, in 3 time intervals: school holidays, classes without exams, and classes with exams.

Results: The authors verified that the systolic arterial pressure and cardiac frequency values checked on exam days were statistically higher (mean of $121.60 \mathrm{mmHg}$ and $85 \mathrm{bpm}$, respectively) than when measured on class days or during vacations. Whereas the systolic arterial pressure and cardiac frequency values measured on class days were significantly lower than those on the other days (mean of $112.75 \mathrm{mmHg}$ and $74.86 \mathrm{bpm}$, respectively).

Conclusion: The authors statistically verified that stress during exam periods had an influence on the arterial blood pressure of medical students, bringing into focus the need for teaching institutions to provide these students with psychosocial and pedagogical support.

Keywords: Medical student; Stress; Education; Blood pressure; Distress

Abbreviations: SAP: Systemic Arterial Pressure; SAH: Systemic Arterial Hypertension; SBH: Brazilian Hypertension Society; EHS: European Hypertension Society; SD: Standard Deviation; AP: Arterial Pressure

\section{Introduction}

Systemic arterial pressure is the product of force exerted by cardiac debit against the walls of blood vessels; and is systolic while the heart pumps blood, and diastolic when it relaxes between beats. Arterial pressure values in healthy adults are below $120 \mathrm{mmHg}$ in the systole and $80 \mathrm{mmHg}$ in the diastole. Cardiac frequency is designated as being the number of times the heart beats per minute, and its normal rate at rest, variable from person to person, is from 60 to 100 [1].

Various factors may change the arterial blood pressure, and one of the most common products of this change is systemic arterial hypertension (SAH). This is characterized by sustained high levels of arterial pressure above $140 \mathrm{mmHg}$ systolic and above $90 \mathrm{mmHg}$ diastolic, and may have an influence on homeostasis [2].

Globally, cardiovascular diseases cause 17 million deaths/year, of these, 9.4 million results from SAH complications. In 2008, worldwide,
$40 \%$ of adult's $\geq 25$ years of age were diagnosed with hypertension, resulting in the number of 1 billion individuals [3].

Among the various risk factors for the development of SAH and circulatory diseases, the following are cited: family history, age, gender, ethnicity; and those that can be controlled: excess weight, high sodium consumption, alcoholism, smoking, sedentarism, psychosocial stress, socioeconomic factors, sleep apnea and other environmental conditions that tend to contribute to an unhealthy lifestyle [1].

A risk factor greatly involved in the change in arterial pressure and cardiac frequency, stress consists of a pathological change in response to environmental stimuli. This causative agent has become more common in triggering SAH due to the transformation in the social sphere, in which sedentary habits are associated with long working days, eating habits, violence, and so many other factors that contribute to emotional wear [4].

Bearing in mind the pathological effects of stress and their consequences relative to arterial pressure and pulse rate, the high level of stress experienced by medical students must be taken into consideration. The fact that this group is submitted to long days of classes, long hours of study and pressure both in the academic medium and family circle, factors that converge and lead to a high incidence of anguish/distress. This distress could have a profound impact on the professional and personal life of students, and leave them more vulnerable to developing depressive conditions. By virtue of this 
stressful situation, this class may present reduction in academic performance, social isolation, exhaustion, and even greater predisposition to developing various pathologies, since the immune system is highly influenced by the emotional and psychological state $[5,6]$.

\section{Methods}

Initially, the project of the present study was sent to the Committee on Ethics in Researches with Human Beings, and after issue of the report favorable to conducting the study, the procedures described hereafter were carried out.

The sample was composed of 109 students out of the total of 300 enrolled in the undergraduate course in Medicine by the University of Itaúna, Minas Gerais, Brazil, comprised of the $1^{\text {st }}$ and $7^{\text {th }}$ academic periods in the 1st semester of 2016. The sample number was obtained after including students who showed they were in favor of participating in the study. Afterwards, arterial pressure was recorded in 3 time intervals: during school holidays; an academic period without exams, and an academic period during exams. The authors emphasize that at this institution, exams on all the disciplines generally take place during the period of 1 week.

Authorization was obtained from the Coordinator of the Course in Medicine of the University, to conduct the research on the premises of the faculty.

The inclusion criteria were as follows: medical students duly enrolled and attending courses between the $1^{\text {st }}$ and $7^{\text {th }}$ period at the University of Itaúna; who were in agreement with the Term of Free and Informed Consent, and who authorized the measurements to be taken in the periods determined.

The exclusion criterion was students of the course in Medicine of the University of Itaúna who were attending courses higher than the seventh period, and students who did not authorize their participation in the study.

A questionnaire was applied, covering the students' identification data, follow-up chart of measurement, and questions related to factors that affected the level of arterial pressure and that could have an influence on the research, such as hereditary cardiovascular disease, age, gender, sedentarism, alcohol consumption, smoking, use of medications during the exam periods.

A term of free and informed consent was written in accordance with the criteria established by the University of Itaúna, with the procedures related to the research, risks and benefits detailed in easily to understandable language, which each participant signed, and received a copy of equal content signed by the researchers.

The arterial pressure monitor used in the study was the automatic (brachial) Omron HEM-7113-BR, approved by the Brazilian Hypertension Society (SBH) ("Sociedade Brasileira de Hipertensão") and European Hypertension Society (EHS), equilibrated and checked in accordance with the ANVISA No. 80047300345 specification.

The measurements were taken by the same operator, who was trained and calibrated with regard to the pressure monitor manufacturer's specifications, so that this procedure would not interfere in the students' academic obligations.

Measurement was taken after a 30-minute rest, with 2 measurements being taken with an interval of 2 minutes between them, in accordance with the cardiology guidelines of the American Heart Association. Afterwards the arithmetical mean values of systolic and diastolic arterial pressure were established.

After obtaining the measurements, the results were distributed in an Excel (Microsoft) table, and were afterwards submitted to statistical tests for the analysis of variance and descriptive statistics of the findings with reference to the questions in the questionnaire. The software used to perform the statistical tests were Graph Pad Prism 5.0 (GraphPad Software Inc., La Jolla, CA, USA) (Publisher's name: "Pontifícia Universidade Católica de Minas Gerais", Belo Horizonte, Brazil).

\section{Results}

Of the 109 patients, with a mean age of 21.53 years (SD 2.95), who participated in this study $72(66.05 \%)$ were of the female, and 37 (33.95\%) of the male gender. The frequency of relevant medical data was tabulated (Table 1).

No data relative to Diabetes, AIDS and cardiac and renal insufficiency were put into the table, since the frequency of students with these conditions was zero.

The authors verified that the systolic arterial pressure and cardiac frequency values checked on exam days were statistically higher (mean of $121.60 \mathrm{mmHg}$ and $85 \mathrm{bpm}$, respectively) than when measured on class days or during vacations.

Whereas the systolic arterial pressure and cardiac frequency values measured on class days were significantly lower than those on the other days (mean of $112.75 \mathrm{mmHg}$ and $74.86 \mathrm{bpm}$, respectively).

\begin{tabular}{|l|l|}
\hline Characteristics of the sample & Number of Individuals ( $\mathbf{n})$ \\
\hline Female Sex & $\mathrm{n}=72(66.05 \%)$ \\
\hline Male Sex & $\mathrm{n}=37(33.95 \%)$ \\
\hline Age of sample (years) & $21.53( \pm 2.95)$ \\
\hline Hypertension & $1(0.91 \%)$ \\
\hline Anti-Hypertensive Medication & $2(1.82 \%)$ \\
\hline History of Hypertension & $59(54.12 \%)$ \\
\hline Dyslipidemia & $1(0.91 \%)$ \\
\hline Sedentarism & $51(46.78 \%)$ \\
\hline Smoking & $4(3.66 \%)$ \\
\hline Use of medications in exam periods & $26(23.85 \%)$ \\
\hline
\end{tabular}

Table 1: Characterization of sample composed of 109 individuals.

Only for diastolic pressure was there no statistical difference between measurements on class days and vacation days, and between vacation days and exam days. However, there was statistical difference between values of measurement days and exam days $(66.32 \mathrm{mmHg}$ and $69.87 \mathrm{mmHg}$, respectively).

For this purpose, the analysis of variance (One-Way ANOVA Tukey, was used, with a level of significance of $p<0.01$ ) (Table 2 and Figure 1). 
Citation: Alves De Oliveira T, Rosa KF, Nunes OAV, Alves de Oliveira GA, Manzi FR, et al. (2018) Does the Stress of Exams Period Influence Medical Student's Blood Pressure? A Longitudinal Study. Gen Med (Los Angeles) 6: 307. doi:10.4172/2327-5146.1000307

Page 3 of 4

\begin{tabular}{|c|c|c|c|}
\hline & Class Day & Exam Day & Vacation Day \\
\hline \multicolumn{4}{|c|}{ Systolic Blood Pressure } \\
\hline Mean (SD) & $112.75( \pm 11.46) \mathrm{C}$ & $121.60(0.78) \mathrm{A}$ & $115.22(11.13) \mathrm{B}$ \\
\hline \multicolumn{4}{|c|}{ Diastolic Blood Pressure } \\
\hline Mean (SD) & 66.32 (7.87) B & 69.87 (8.35) A & 67.45 (7.08)AB \\
\hline \multicolumn{4}{|c|}{ Cardiac Frequency } \\
\hline Mean (SD) & $74.89( \pm 11.31) \mathrm{C}$ & $85.67(14.81) \mathrm{A}$ & $76.17(13.16) \mathrm{B}$ \\
\hline
\end{tabular}

Table 2: Comparison of means and standard deviations of systolic arterial blood pressure, diastolic arterial blood pressure and cardiac frequency measurement values.



Figure 1: Means of systolic arterial blood pressure, diastolic arterial blood pressure and cardiac frequency measurement values. Means followed by different letters differed statistically (1-Way ANOVA Tukey, with level of significance of $\mathrm{p}<0.01)$. Systolic and Diastolic arterial pressure values in $\mathrm{mmHg}$ and cardiac frequency in bpm.

\section{Discussion}

The study explored (in the field) the variations in arterial pressure (AP) of medical students in periods of classes, exams and vacations; with a view to the different influence of stress on students in these time intervals. This analysis was shown to be statistically true relative to the hypothesis, in which our results led us to clarity about the problem in palpable values of AP and its relationship with stress. As a result, we discussed the data obtained and their implications with studies of relevance.

The percentage of students who alleged sedentarism (46.78\%) aroused concern due to its association with an unhealthy life style that leads to the onset of homeostatic imbalance, susceptibility to cardiovascular diseases, and excessive suffering from the load of stress experienced. 1 As a similar fact, $23.85 \%$ of the individuals used medications in exam periods due to the necessity of diminishing anxiety and psychological anguish, therefore this was an important marker of the psychic state of this group of individuals.
Systolic arterial pressure and cardiac frequency values were statistically higher in exam periods than in the other periods. Diastolic AP was higher in tests than in classes; all of this was palpable proof of the degree to which stress affects the health of medical students. Physiologically a correlation has been verified between cardiovascular reactivity and vagal suppression as a consequence of prolonged activation of the sympathetic system by stress [7]. Exacerbation of the sympathetic function related to renal and vascular abnormalities acts directly as a risk factor not only for $\mathrm{SAH}$, but also for other cardiovascular diseases [8]. Correlation has also been found between exacerbated vasoconstriction stimuli with imbalance of the immune response, proving greater susceptibility of persons affected by stress [9].

The choice of medicine associated with an unbalanced life style could trigger severe pathological questions, and data obtained in this study corroborate this affirmation. Psychological stress associates predisposing factors such as modern life events, problems related to work and family, social isolation, financial problems and violence. 4 These conditions converge directly on psychological anguish in medical students, because they develop poor academic performance, increase rate of drop-out from medical schools, break-down of personal relationships, abuse of toxic substances and suicide.5,6 Other causes identified such as lack of learning strategy, nights of sleeping badly before exams, and ingestion of unhealthy foods during the period, have also been described in the literature [10]. In addition, the lack of psycho-pedagogical support and flexibility of exam periods may act as risk factors for stress of students, and become a pathological process inherent to medical education.

As more detailed explanations about the subject, the figures analyzed in this study demonstrated the influence of stress on arterial pressure, and this has a relationship with conditions of depression and psychological anguish. When compared with students of the same age, students of medicine have higher rates of symptomatology of depression: a quarter of them presented substantial symptoms [11]. In one study it was also verified that $35 \%$ of the medical interns were positive for significant symptoms of depression, such as cynicism, exhaustion and stress [12] The impact of stress on school performance may diminish the capability of concentration; motivation and cognitive capacity of students, with women being those most affected $[13,14]$. In short, the data obtained in this study fuse with those of other studies and statistically prove à prior how exam periods and 
stress throughout the course degrade the health of students of medicine.

The higher number of women present in this study (66.05\%) was in agreement with the results of other similar researches: Mata et al. obtained $65 \%$ of women in their analysis about depression among medical interns. Eva et al. recorded $64 \%$ in their study about the prevalence of stress in medical students. These data converge on the eminent increase in the participation of women in contemporary medicine which, according to the Association of American Medical Colleges, evolved from $31.4 \%$ in 1982 to $47 \%$ in 2012 and has increased every year [12,15-17].

As a curiosity for prevention of this problem, in a study conducted with 115 students, those with a larger number of friends were less anxious and depressive. Moreover, the women obtained the highest stress index when compared with men, and other biological gender and social factors may also be involved [17]. An eminent datum that corroborated the situation of stress experienced, according to The American Foundation for Suicide Prevention, showed that approximately 300 American doctors commit suicide per year, with the risk for men being 1.41 and risk for women being 2.27 times higher than that for others of different professions $[18,19]$.

\section{Conclusion}

The statistical increase in AP and cardiac frequency proved by this study demonstrated the degree of direct interference of stress in the cardiovascular condition of the students, not only for SAH, but for any and all their cardiac, immunological, renal and psychosocial conditions that work in harmony.

Therefore, the students' health is stated as a right to be considered by the medical curriculum; and this must be protected and supported so that all the wear suffered by students will not be so severe that it would be capable of harming learning, and the students' responsibility towards society, the family environment and their interpersonal relationships, particularly their own personal and spiritual well-being. In view of the foregoing considerations, it is necessary to promote an efficient education, with social responsibility towards the medical class, composed of individuals subjected to a greater dimension of accountability because of their zeal for care of life.

\section{Ethics Approval and Consent to Participate}

Research Ethics Committee 5144 - University of Itaúna, Minas Gerais, Brazil. Corporate Tax Registration No. (CNPJ): 21.256.425/0001-36. CAAE: 53457216.0.0000.5144. Report: Approved, Number: 1.502 .530 .

\section{Authors' Contributions}

OAVN - worked on obtaining the data, KFR worked on obtaining the data, TAO studied about the subject-matter and write article, GAAO managed roles of each author and assisted in the article creation - FRM - analyzed and interpreted the data regarding the systemic arterial pressure. All authors read and approved the final manuscript.

\section{References}

1. American Heart Association, American Stroke Association (2017) Understanding and managing high blood pressure. Revised 2014.

2. Mancia G, Fagard R, Narkiewicz K (2013) 2013 ESH/ESC Guidelines for the management of arterial hypertension: The Task force for the management of arterial hypertension of the European society of hypertension (ESH) and of the European society of cardiology (ESC). J Hypertens 31: 1281-1357.

3. World Health Organization (2017) A global brief on hypertension. Revised April 2013.

4. Gasperin D, Netuveli G, Dias-da-Costa JS, Patussi MP (2009) Effect of psychological stress on blood pressure increase: A meta-analysis of cohort studies. Cad Saude Publica 25: 715-726.

5. Dyrbye LN, Thomas MR, Shanafelt TD (2005) Medical student distress: Causes, consequences, and proposed solutions. Mayo Clin Proc 80: 1613-1622.

6. Enns MW, Cox BJ, Sareen J, Freeman P (2001) Adaptive and mal adaptive perfectionism in medical students: A longitudinal investigation. Medical Education 35: 1034-1042.

7. Stansfeld S, Marmot MG (2002) Stress and the heart: Psychosocial pathways to coronary heart disease. Bio Med Journal Books, Williston, Vermont, USA.

8. Dartora DR, Moraes AO, Cruz PL, Sangaleti C, Irigoyen MC (2015) Sistema nervoso autônomo, hipertensão e inflamação. Rev Hipertens 18: 11-19.

9. Trott DW, Harrison DG (2014) The immune system in hypertension. Trans Am Clin Climatol Assoc 125: 130-138.

10. Gajalakshmi G, Kavitha U, Anandarajan B, Chandraseka M (2012) A study to analyze various factors contributing to stress in first year MBBS students during examination. Int J of Biomed \& Adv Res 3: 700-703.

11. Slonim J, Kienhuis M, Di Benedetto M, Reece J (2015) The relationships among self-care, dispositional mindfulness, and psychological distress in medical students. Med Educ Online 20: 1-13.

12. Mata DA, Ramos MA, Kim MM, Guille C, Sen S (2016) In their own words: An analysis of the experiences of medical interns participating in a prospective cohort study of depression. Acad Med 91: 1244-1250.

13. Dusselier L, Dunn B, Wang Y, Shelley MC, Whalen DF (2005) Personal, health, academic, and environmental predictors of stress for residence hall students. J Am Coll Health. 54: 15-24.

14. Pradhan, Mendinca NL, Kar M (2014) Evaluation of examination stress and its effect on cognitive function among first year medical students. J Clin Diagn Res 8: BC05-BC07.

15. Eva EO, Islam MZ, Mosaddek AS (2015) Prevalence of stress among medical students: A comparison study between public and private medical schools in Bangladesh. BMC Res Notes 8: 327.

16. Lautenberger DM, Dandar VM, Raezer CL, Sloane RA (2017) The state of women in academic medicine. Association of American Medical Colleges, Washington, D.C., USA.

17. Association of American Medical Colleges (2017) U.S Medical school applicants and students 1982-1983 to 2011-2012.

18. Qamar K, Khan NS, Kiani MRB (2015) Factors associated with stress among medical students. J Pak Med Assoc 65: 753-755.

19. American Foundation for Suicide Prevention (2017) Ten facts about physician suicide and mental health. 